\title{
Carriers of the TCF7L2 rs7903146 TT genotype have elevated levels of plasma glucose, serum proinsulin and plasma gastric inhibitory polypeptide (GIP) during a meal test
}

\author{
A. P. Gjesing • L. L. Kjems • M. A. Vestmar • \\ N. Grarup • A. Linneberg • C. F. Deacon • J. J. Holst • \\ O. Pedersen $\cdot$ T. Hansen
}

Received: 17 May 2010 / Accepted: 19 August 2010/Published online: 19 October 2010

(C) Springer-Verlag 2010

\begin{abstract}
Aims/hypothesis The transcription factor 7-like 2 (TCF7L2) rs7903146 T allele associates with type 2 diabetes in several populations, possibly mediated via decreased incretin secretion and/or action and altered beta and alpha cell function. We aimed to study circulating levels of glucose, proinsulin, insulin, C-peptide, glucagon, glucagon-like peptide-1 (GLP-1), glucagon-like peptide-2 (GLP-2) and gastric inhibitory polypeptide (GIP) among individuals carrying the high-risk rs7903146 TT genotype and lowrisk CC genotype following a meal test.

Methods A meal challenge was performed in 31 glucosetolerant men (age $54 \pm 7$ years and BMI $26 \pm 3 \mathrm{~kg} / \mathrm{m}^{2}$ ) with rs7903146 TT genotype and 31 glucose-tolerant age- and BMI-matched men with $\mathrm{CC}$ genotype (age $53 \pm 6$ years and
\end{abstract}

A. P. Gjesing and L.L. Kjems contributed equally to this study.

Electronic supplementary material The online version of this article (doi:10.1007/s00125-010-1940-4) contains supplementary material, which is available to authorised users.

A. P. Gjesing $(\varangle) \cdot$ M. A. Vestmar $\cdot$ N. Grarup $\cdot$ O. Pedersen $\cdot$

T. Hansen

Steno Diabetes Center and Hagedorn Research Institute,

Niels Steensens Vej 2,

DK-2820 Gentofte, Denmark

e-mail: apri@hagedorn.dk

L. L. Kjems

Novartis Pharmaceuticals,

New York, USA

\section{A. Linneberg}

Research Centre for Prevention and Health,

Glostrup University Hospital,

Glostrup, Denmark
BMI $26 \pm 3 \mathrm{~kg} / \mathrm{m}^{2}$ ). Serum proinsulin, insulin, C-peptide and plasma glucose, glucagon, GLP-1, GLP-2 and GIP were obtained $0,15,30,45,60,75,90,105,120,135,150$, 180,210 , and $240 \mathrm{~min}$ after ingestion of a standardised breakfast meal.

Results An elevated incremental AUC for plasma glucose was observed among TT genotype carriers (CC carriers $21.8 \pm 101.9 \mathrm{mmol} / 1 \times \min$ vs TT carriers $97.9 \pm 89.2 \mathrm{mmol} /$ $1 \times \min , p=0.001)$. TT carriers also had increased AUCs for proinsulin (CC carriers $6,030 \pm 3,001 \mathrm{pmol} / 1 \times \min$ vs TT carriers $6,917 \pm 4,820 \mathrm{pmol} / 1 \times \mathrm{min}, p=0.03)$, C-peptide $(\mathrm{CC}$ carriers $397.6 \pm 131.9 \mathrm{nmol} / \mathrm{l} \times \min$ vs TT carriers $417.1 \pm$ $109.3 \mathrm{nmol} / \mathrm{l} \times \mathrm{min}, p=0.04)$ and GIP (CC carriers $12,310 \pm$ $3,840 \mathrm{pmol} / 1 \times \min$ vs TT carriers $14,590 \pm 5,910 \mathrm{pmol} / 1 \times$ $\min , p=0.004)$. 
Conclusions/interpretation Middle-aged normoglycaemic individuals carrying the rs7903146 TCF7L2 risk TT genotype show early signs of dysregulated glucose metabolism, decreased processing of proinsulin and elevated GIP secretion following a meal challenge.

Keywords Gene $\cdot$ Incretin $\cdot$ TCF7L2 2 Type 2 diabetes

$\begin{array}{ll}\text { Abbreviations } \\ \text { GIP } & \text { Gastric inhibitory polypeptide } \\ \text { GIP-R } & \text { Gastric inhibitory polypeptide receptor } \\ \text { GLP } & \text { Glucagon-like peptide } \\ \text { GLP-1R } & \text { Glucagon-like peptide-1 receptor } \\ \text { HOMA-IR } & \text { HOMA-insulin resistance } \\ \text { IAUC } & \text { Incremental AUC } \\ \text { ISR } & \text { Insulin secretion rate } \\ \text { TCF7L2 } & \text { Transcription factor 7-like 2 }\end{array}$

\section{Introduction}

Type 2 diabetes mellitus is a complex disease that results from the interplay between adverse health behaviour and genetic risk factors [1]. More than 20 validated common type 2 diabetes susceptibility loci have been identified, of which the majority have been shown to associate with pancreatic islet cell dysfunction, insulin resistance or obesity [2-7]. The rs7903146 transcription factor 7-like 2 (TCF7L2) T allele has shown the strongest association with type 2 diabetes to date, with a per allele odds ratio of 1.4 [8]. However, despite major efforts to elucidate the underlying mechanisms whereby this variant increases the risk of type 2 diabetes, its functional impact and its specific role in disease pathogenesis are still unclear.

TCF7L2 spans a $\sim 216 \mathrm{~kb}$ region on chromosome 10 , and consists of 17 exons [9, 10]. Tissue-specific splicing patterns have been identified; the pancreatic islet and colon display a unique splice isoform containing exons 4 and 15 $[10,11]$. Rs 7903146 is located between exons 4 and 5, and may influence the splicing pattern of TCF7L2 [10].

TCF7L2 is a transcription factor that is part of the Wnt/ $\beta$-catenin signalling pathway. This is a ubiquitous signalling pathway that ultimately activates transcriptional programmes. Thus, Wnt signalling may promote mechanisms such as cell proliferation, tissue expansion and differentiation [12].

As a consequence of the central function of TCF7L2, several mechanisms have been suggested to explain the effect of variants in TCF $7 L 2$ on the development of type 2 diabetes. One hypothesis is based on the involvement of TCF7L2 in the gut $\mathrm{L}$ and $\mathrm{K}$ cells in the transcription of $G C G$, encoding glucagon-like peptide-1 (GLP-1), [13] and of GIP [14], respectively, connecting TCF7L2 to the entero-insular axis and $G C G$ transcription in alpha cells encoding glucagon [15]. Patients with type 2 diabetes have impaired insulin responses following a meal or an oral glucose stimulus and defective incretin secretion has been shown to contribute to this [16]. It has, however, also been suggested that a defect in glucose sensing of the beta cell could impair glucose-mediated insulin secretion, possibly leading to increased glucagon levels [17].

However, previous studies have failed to detect reduced secretion of GLP-1 following an oral glucose load in T allele carriers of the TCF7L2 rs7903146 variant [18-20], and an increased level of glucagon [21].

A second hypothesis is based on in silico analysis suggesting that the rs7903146 T allele of TCF7L2 might act through decreased transcription of PCSK1 and PCSK2 [22]. These genes encode convertases involved in the processing of GLP-1, GLP-2 and gastric inhibitory polypeptide (GIP) in the intestinal $\mathrm{L}$ and $\mathrm{K}$ cells, and of glucagon in the alpha cells and proinsulin in the beta cells of the pancreas. In support of the latter hypothesis, several studies have shown increased proinsulin levels as well as increased proinsulin/ insulin ratios in $T C F 7 L 2$ risk allele carriers [22-26].

An additional hypothesis is based on the finding that pancreatic islets from type 2 diabetic patients had a lower levels of glucagon-like peptide-1 receptor (GLP-1R) and gastric inhibitory polypeptide receptor (GIP-R) and did not contain detectable amounts of TCF7L2 protein by immunofluorescence staining. Furthermore, downregulation of GLP-1R and GIP-R was seen after treatment with small interfering TCF7L2 in isolated human pancreatic islets [27]. Several studies have observed impaired GLP-1-induced insulin secretion $[19,21]$ and a diminished incretin effect among rs7903146 $\mathrm{T}$ allele carriers [28] without identifying reduced levels of GLP-1 and GIP [18], supporting the existence of a defect in the transcription of incretin receptors leaving the beta cell resistant to incretin hormones.

In contrast, other studies have reported islet-specific upregulation of TCF7L2 [29] and increased levels of TCF7L2 mRNA [28] in type 2 diabetic patients. The latter study also found a positive correlation between the mRNA levels of TCF7L2 and the insulin gene; however, in this study a lower in vitro glucose-stimulated insulin release was found, suggesting that TCF7L2 influences posttranscriptional events of insulin production [28]. Thus, despite the intensive investigation of the actions whereby variants within $T C F 7 L 2$ increase the risk of type 2 diabetes, the pathogenetic contribution of this locus to increased type 2 diabetes risk is far from clear.

The aim of this study was to examine the impact of the TCF7L2 rs7903146 on incretin secretion, incretin action and insulin secretion following a standardised meal challenge test in white healthy adults with TCF7L2 rs7903146 low-risk $\mathrm{CC}$ and high-risk TT genotypes, respectively. 


\section{Methods}

Study participants This study was carried out in 62 men recruited from the Inter99 population-based study [30]. Thirty-one were homozygous for the TCF7L2 rs7903146 high-risk $\mathrm{T}$ allele and 31 were age- and BMI-matched individuals, homozygous for the low-risk TCF7L2 C allele (Table 1). They were all glucose tolerant following a standard OGTT when examined in the Inter99 study 7 and 2 years prior to participation in the present study. All individuals agreed to participate and gave oral and written consent. The study was approved by the Copenhagen County Ethical Committee and was conducted according to the principles of the Helsinki Declaration.

Genotyping Genotyping of TCF7L2 rs7903146 was performed in duplicate in all participants as previously described by Helgason and colleagues [8] and by Rung and colleagues [7]. No mismatches were observed.

Standardised meal challenge The participants consumed a test meal consisting of $50 \mathrm{~g}$ white bread, $50 \mathrm{~g}$ black bread, $10 \mathrm{~g}$ butter, $40 \mathrm{~g}$ cheese, $20 \mathrm{~g}$ sugar-free jam and $200 \mathrm{ml}$ milk ( $34 \%$ fat, $47 \%$ carbohydrate, $19 \%$ protein), comprising a total of $2,370 \mathrm{~kJ}(566 \mathrm{kcal})$. The meal was consumed within 15 min. Arterialised venous blood was drawn 20, 10 and $0 \mathrm{~min}$ before and 15, 30, 45, 60, 75, 90, 105, 120, 135, 150, 180,210 and $240 \mathrm{~min}$ after ingestion of the meal. Blood was sampled into fluoride tubes for plasma glucose analysis and into tubes containing heparin or EDTA (6 pmol/1) plus aprotinin (500 kallikrein inhibitor units/ml blood; Trasylol, Bayer, Leverkusen, Germany) and a specific dipeptidyl peptidase-4 inhibitor (valine-pyrrolidide, $0.01 \mathrm{mmol} / \mathrm{l}$ final concentration; Novo Nordisk, Bagsværd, Denmark) for hormone analysis.

Biochemical analyses Blood samples were drawn after a $12 \mathrm{~h}$ overnight fast. Plasma glucose was analysed by a

Table 1 Anthropometric and biochemical description of 62 individuals included according to TCF7L2 rs7903146 CC and TT genotype

\begin{tabular}{lccc}
\hline Characteristic & CC & TT & $p$ value \\
\hline Age (years) & $53.6 \pm 6.9$ & $53.3 \pm 6.3$ & 0.7 \\
Weight $(\mathrm{kg})$ & $85.0 \pm 11.9$ & $84.6 \pm 10.1$ & 0.9 \\
Height $(\mathrm{cm})$ & $180 \pm 6.1$ & $182 \pm 7.9$ & 0.3 \\
BMI $\left(\mathrm{kg} / \mathrm{m}^{2}\right)$ & $26.3 \pm 3.1$ & $25.7 \pm 2.5$ & 0.09 \\
Waist $(\mathrm{cm})$ & $95.8 \pm 7.2$ & $96.2 \pm 7.8$ & 0.9 \\
Waist-hip ratio & $0.9 \pm 0.04$ & $0.9 \pm 0.1$ & 1.0 \\
HOMA-IR & $9.9 \pm 6.1$ & $9.6 \pm 6.2$ & 1.0 \\
\hline
\end{tabular}

Data are means $\pm \mathrm{SD}$

$p$ values were calculated using a paired $t$ test glucose oxidase method (Granutest, Merck, Darmstadt, Germany) with a detection limit of $0.11 \mathrm{mmol} / 1$ and intraand interassay coefficients of variation of $<0.8$ and $<1.4 \%$, respectively. Serum C-peptide was measured using a time-resolved fluoroimmunoassay with the AutoDELFIA C-peptide kit, having a detection limit of $5 \mathrm{pmol} / 1$ and intra- and interassay coefficients of variation of $<4.7 \%$ and $<6.4 \%$, respectively. Serum insulin (excluding des $[31,32]$ and intact proinsulin) was measured using the AutoDELFIA insulin kit (Perkin-Elmer, Wallac, Turku, Finland) with a detection limit of $3 \mathrm{pmol} / \mathrm{l}$ and with intraand interassay coefficients of variation of $<3.2 \%$ and $<4.5 \%$, respectively. Proinsulin was measured using a sandwich ELISA that measures intact proinsulin as well as the four metabolites: split(32-33), des(31,32), split(65-66) and des(64,65)-proinsulin. The detection limit is $0.3 \mathrm{pmol} / 1$ and intra- and interassay coefficients of variation are $<6.2 \%$ and $<8.7 \%$, respectively. This assay has no crossreactivity with insulin, C-peptide, IGF-I or IGF-II. Total plasma $\mathrm{COOH}$-terminal amidated GLP-1 was assayed by radioimmunoassay using polyclonal antiserum 89390 (raised in rabbits). This antibody has an absolute requirement for the amidated C-terminus of GLP-1, and thus does not cross-react with $\mathrm{C}$-terminally truncated metabolites or with glycine-extended forms; it therefore mainly reacts with GLP-1 of intestinal origin. The assay has a detection limit of $\sim 1 \mathrm{pmol} / 1$ and an $\mathrm{ED}_{50}$ of $25 \mathrm{pmol} / \mathrm{l}$. Intra- and interassay coefficients of variation are $<6 \%$ and $<15 \%$, respectively [31]. Plasma levels of intact $\left(\mathrm{NH}_{2}\right.$-terminal) GIP were assayed by radioimmunoassay using polyclonal antiserum 98171 (raised in rabbits) that is $\mathrm{NH}_{2}$-terminally directed and does not recognise $\mathrm{NH}_{2}$-terminally truncated peptides. The detection limit is $<5 \mathrm{pmol} / \mathrm{l}$ with an $\mathrm{ED}_{50}$ of $48 \mathrm{pmol} / \mathrm{l}$, and intra- and interassay coefficients of variation were $<6 \%$ and $<15 \%$, respectively [32]. Plasma GLP-2 was measured by radioimmunoassay employing antiserum 92160 and standards of human GLP-2 (proglucagon 126-158, Novo Nordisk, Bagsværd, Denmark) and monoiodinated Tyr-12 GLP-2, specific activity $>70 \mathrm{MBq} / \mathrm{nmol}$. The antiserum was directed against the N-terminus of GLP-2 and therefore measures only fully processed active GLP-2 of intestinal origin [33]. The plasma glucagon radioimmunoassay was directed against the $\mathrm{C}$-terminus of the glucagon molecule (antibody 4305) and therefore mainly measures glucagon of pancreatic origin [34].

Statistical analyses A paired $t$ test was applied to test for differences between genotype pairs. For these analyses measures of serum insulin were logarithmically transformed prior to analysis. A linear regression model was applied in order to perform analyses adjusted for fasting plasma glucose, age and BMI. In the linear regression model measures of serum insulin were log-transformed prior to 
analysis. A $p$ value of less than 0.05 was considered statistically significant.

Statistical power The sample size determination is based on a two-sample two-sided $t$ test at $5 \%$ significance level. A total of $2 \times 30$ participants will provide a power of $90 \%$ power to detect a difference of $280 \mathrm{pmol} / \mathrm{kg}$ (about 24\%) in AUC for insulin secretion rate (ISR) between the two groups by the use of a paired $t$ test. By using a regression model we have a power of $90 \%$ power to detect an allelespecific difference of $55 \%$ when estimated by the previously described method for calculating power [5]. This corresponds to a difference of $57 \mathrm{mmol} / 1 \times \min$ AUC for

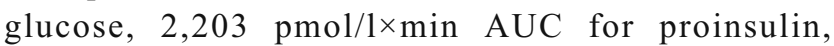
66,294 pmol/1×min AUC for C-peptide, 2,799 $\mathrm{pmol} / 1 \times \min$ AUC for GIP, 1,425 pmol/1×min AUC for GLP-1, $795 \mathrm{pmol} / 1 \times \min$ AUC for GLP-2 and $639 \mathrm{ng} / \mathrm{l} \times \min$ AUC for glucagon between the two groups.

Calculations of physiological measures The AUCs were calculated by the trapezoidal method, and incremental AUCs (IAUCs) were calculated by subtraction of the

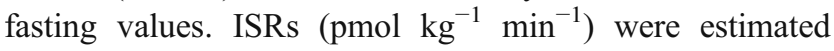
from measured serum C-peptide concentrations using deconvolution [35]. This mathematical operation calculates the secretion rate based on pre-defined C-peptide kinetic parameters from each individual's weight, height, age, sex and clinical status (glucose tolerance and obesity status) determined in a population-based study [35, 36]. The software ISEC, which implements all these factors [37], was applied for the present study.

\section{Results}

The study was performed in a matched design where TCF7L2 rs7903146 CC allele carriers were selected in order to match TT allele carriers for age and BMI. The two groups were similar in relation to measures of age, body composition and HOMA-insulin resistance (IR; Table 1).

Levels of plasma glucose, serum insulin, serum proinsulin, serum C-peptide, plasma glucagon, intact plasma GIP, total plasma GLP-1 and plasma GLP-2 during a meal test were compared between the $\mathrm{CC}$ group and the TT group (Fig. 1 and Electronic supplementary material [ESM] Fig. 1). Preprandial fasting measures of plasma glucose were found to be significantly lower among the TT carriers, with inter-pair differences of $0.31 \mathrm{mmol} / 1$ (95\% CI $0.13-$ $0.50 \mathrm{mmol} / \mathrm{l}$ ) as well as levels at 15,30 and $240 \mathrm{~min}$ postprandially with inter-pair differences of $0.36 \mathrm{mmol} \mathrm{l}^{-1}$ (95\% CI $0.08-0.6), 0.60 \mathrm{mmol} / \mathrm{l}(95 \%$ CI $0.2-1.05)$ and $0.17 \mathrm{mmol} / 1$ (95\% CI $0.02-0.3)$, respectively. In contrast, significantly higher levels of GLP-2 were observed at
20 min preprandial (inter-pair difference $5.6 \mathrm{pmol} / 1$ [95\% CI 2.3-8.9]) and 10 min preprandial (inter-pair difference $4.8 \mathrm{pmol} / 1$ [95\% CI 1.22-8.46]) among TT allele carriers. In addition, postprandial plasma GLP-2 at 60 min (inter-pair difference $4.6 \mathrm{pmol} / 1$ [95\% CI $0.02-9.3]$ ) was significantly elevated among TT carriers. None of the remaining measures of glucose homeostasis was significantly different using a $t$ test.

Also fasting levels of total plasma cholesterol, plasma triacylglycerols, plasma HDL-cholesterol, plasma LDLcholesterol and plasma VLDL-cholesterol were investigated; however, we did not find any significant differences in these lipids between the two groups.

As the fasting plasma glucose level among $\mathrm{T}$ allele carriers was significantly lower than that in $\mathrm{CC}$ allele carriers, we performed linear regression, adjusting for fasting plasma glucose as well as age and BMI. Adjusting for this confounder resulted in the detection of significantly higher preprandial levels of serum proinsulin, serum Cpeptide, plasma GIP and plasma GLP-2 among carriers of the risk allele (Fig. 1 and ESM Fig. 1). However, all analyses were also performed including adjustments for HOMA-IR, which resulted in the associations with proinsulin and Cpeptide disappearing even though the variant did not significantly affect this estimate of insulin resistance.

Furthermore, postprandial levels of plasma glucose, serum proinsulin, serum C-peptide and plasma GIP were significantly elevated among TT homozygous individuals (Fig. 1 and ESM Fig. 1).

The AUC and IAUC for glucose, insulin, proinsulin, Cpeptide, glucagon, GIP, GLP-1 and GLP-2 were calculated (Table 2). TT carriers had a significantly higher IAUC and AUC for glucose, AUC and IAUC for GIP, AUC and IAUC for proinsulin and AUC for C-peptide compared with $\mathrm{CC}$ carriers (Table 2).

One way of assessing whether incomplete processing of proinsulin could be involved in disease pathogenesis is to examine differences in proinsulin AUC/insulin AUC ratios between the two groups. However, we did not observe any significant difference (Table 2).

ISRs were calculated. Fasting levels of ISR were significantly elevated among carriers of the TT genotype as well as levels at 90 and 105 min postprandially. However, we did not find any genotypic influence on AUC or IAUC for the ISR.

\section{Discussion}

Carriers of the rs7903146 TCF7L2 diabetes risk T allele present an increased IAUC for plasma glucose in spite of a significantly lower fasting plasma glucose level among these individuals. Additionally, we found that the AUCs for circulating levels of proinsulin, C-peptide and GIP following a meal challenge were increased in the risk $\mathrm{T}$ allele carriers. 
Fig. 1 Measures of plasma glucose (a), serum proinsulin (b), serum C-peptide (c), serum insulin (d), plasma GIP (e), and plasma GLP-1 (f) in 62 carriers of TCF7L2 rs7903146 CC and TT genotypes, respectively, who underwent a standardised meal test. ${ }^{*} p<0.05$ and $* * p<0.01$ obtained from a paired $t$ test; ${ }^{\dagger} p<0.05$ and ${ }^{\dagger \dagger} p<0.01$ obtained from a linear regression model. Red line, TT genotype carriers; black line, $\mathrm{CC}$ genotype carriers
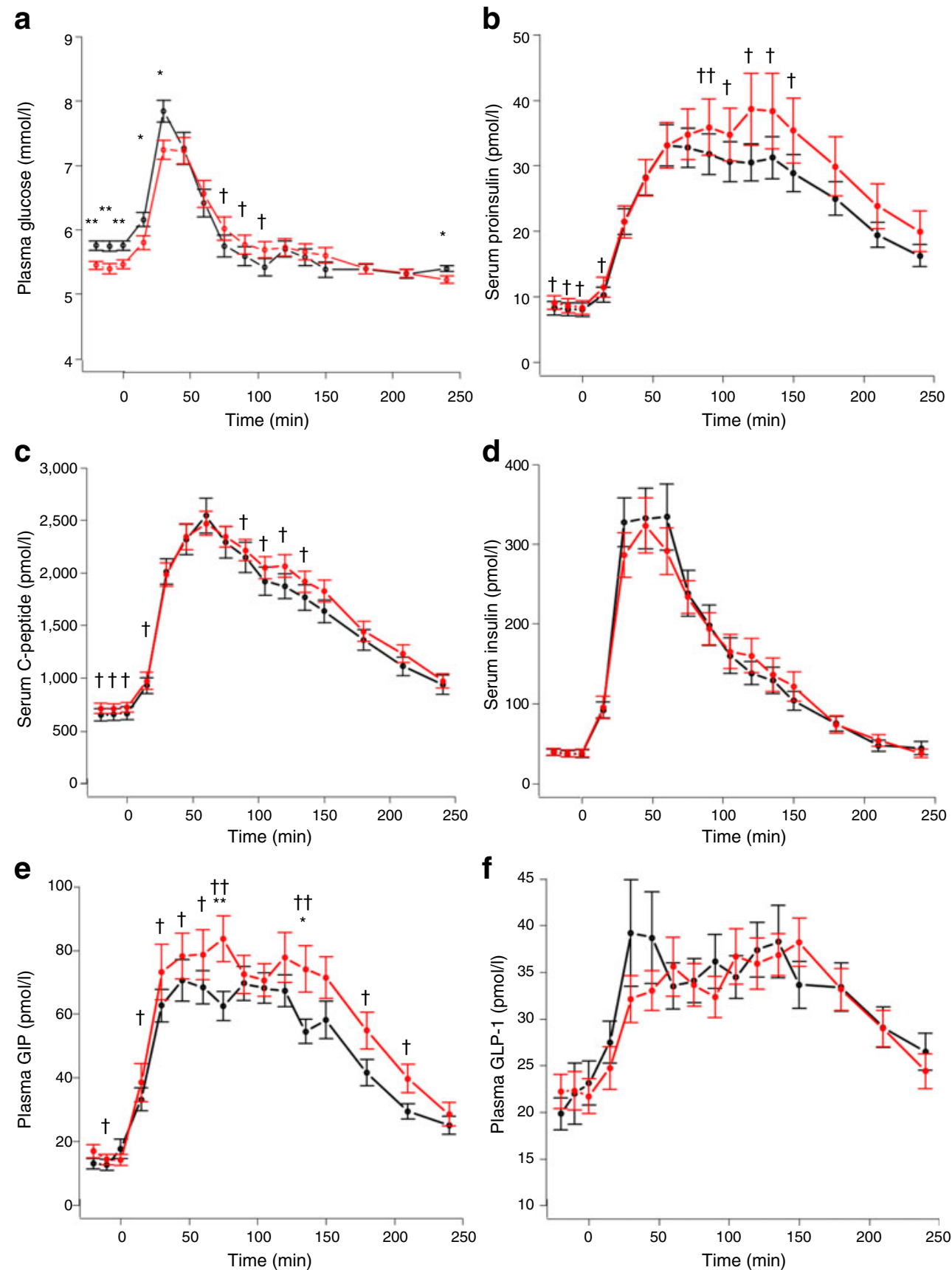

However, the association with C-peptide was not consistent; thus, the nominally significant association may be a chance finding.

It was unexpected that we observed a decrease in fasting plasma glucose level among TT genotype carriers. This finding may be due to the design of the study, whereby middle-aged glucose-tolerant TT genotype men, who may have compensatory mechanisms that decrease their risk of developing type 2 diabetes, were studied. If individuals with impaired glucose regulation or overt type 2 diabetes had been included in the study, it is possible that a more obvious beta cell secretory defect may have been unmasked. The present study also only included men, and we may have had a different outcome had the study also included women.

Previous studies have reported either no association between variants in TCF7L2 and impaired insulin sensitivity [21, 38-43] or an association with increased insulin sensitivity [19, 44]. Thus, the elevated plasma glucose levels in the postprandial state are not likely to be due to impaired insulin action in the peripheral tissues. Therefore, we hypothesise that the elevated postprandial glycaemia is mediated by an impaired pancreatic beta cell function.

In line with previous studies $[19,22]$, the linear regression modelling revealed significantly elevated serum 
Table 2 AUC results for 62 carriers of the TCF7L2 rs7903146 CC or TT genotype who underwent a standardised meal test

\begin{tabular}{|c|c|c|c|c|}
\hline Variable & CC genotype & TT genotype & $p$ value (pair test) & $p$ value (linear regression) ${ }^{\mathrm{a}}$ \\
\hline \multicolumn{5}{|l|}{ AUC glucose $(\mathrm{mmol} / 1 \times \min )$} \\
\hline AUC glucose $240 \mathrm{~min}$ & $1,403 \pm 110$ & $1,403 \pm 100$ & 1.0 & 0.04 \\
\hline IAUC glucose $240 \mathrm{~min}$ & $21.8 \pm 101.9$ & $97.9 \pm 89.2$ & 0.001 & 0.04 \\
\hline \multicolumn{5}{|l|}{ AUC insulin $(\mathrm{pmol} / 1 \times \min )$} \\
\hline AUC insulin $240 \min ^{\mathrm{b}}$ & $36,401 \pm 19,655$ & $35,713 \pm 19,855$ & 0.9 & 0.2 \\
\hline IAUC insulin $240 \mathrm{~min}^{\mathrm{b}}$ & $27,252 \pm 14,943$ & $26,222 \pm 15,308$ & 0.8 & 0.4 \\
\hline \multicolumn{5}{|l|}{ AUC C-peptide $(\mathrm{pmol} / 1 \times \min )$} \\
\hline AUC C-peptide $240 \mathrm{~min}$ & $397,604 \pm 131,923$ & $417,140 \pm 109,276$ & 0.5 & 0.04 \\
\hline IAUC C-peptide $240 \mathrm{~min}$ & $239,021 \pm 68,736$ & $244,967 \pm 64,925$ & 0.7 & 0.2 \\
\hline \multicolumn{5}{|l|}{ AUC proinsulin $(\mathrm{pmol} / 1 \times \min )$} \\
\hline AUC proinsulin $240 \mathrm{~min}$ & $6,033 \pm 3,001$ & $6,917 \pm 4,820$ & 0.4 & 0.03 \\
\hline IAUC proinsulin $240 \mathrm{~min}$ & $4,085 \pm 1,961$ & $4,805 \pm 3,682$ & 0.3 & 0.05 \\
\hline \multicolumn{5}{|l|}{ AUC glucagon (ng/1× min) } \\
\hline AUC glucagon $240 \mathrm{~min}$ & $2,598 \pm 1,116$ & $2,336 \pm 1,208$ & 0.2 & 0.7 \\
\hline IAUC glucagon $240 \mathrm{~min}$ & $906 \pm 723$ & $640 \pm 615$ & 0.1 & 0.2 \\
\hline \multicolumn{5}{|l|}{ AUC GLP-1 (pmol/1× min) } \\
\hline AUC GLP-1 240 min & $7,978 \pm 3,039$ & $7,733 \pm 2,092$ & 0.6 & 0.9 \\
\hline IAUC GLP-1 $240 \mathrm{~min}$ & $2,736 \pm 2,448$ & $2,406 \pm 2,219$ & 0.6 & 0.3 \\
\hline \multicolumn{5}{|l|}{ AUC GIP (pmol/1× min) } \\
\hline AUC GIP $240 \mathrm{~min}$ & $12,313 \pm 3,840$ & $14,585 \pm 5,905$ & 0.04 & 0.004 \\
\hline IAUC GIP $240 \mathrm{~min}$ & $8,857 \pm 4,354$ & $10,921 \pm 5,184$ & 0.06 & 0.02 \\
\hline \multicolumn{5}{|l|}{ AUC GLP-2 (pmol/1× min) } \\
\hline AUC GLP-2 240 min & $5,280 \pm 1,040$ & $5,812 \pm 1,738$ & 0.1 & 0.4 \\
\hline IAUC GLP-2 $240 \mathrm{~min}$ & $1,698 \pm 1,461$ & $1,221 \pm 2,015$ & 0.3 & 0.08 \\
\hline \multicolumn{5}{|l|}{ AUC ISR (pmol/kg) } \\
\hline AUC ISR $240 \mathrm{~min}^{\mathrm{b}}$ & $1,126 \pm 364$ & $1,189 \pm 300$ & 0.4 & 0.09 \\
\hline IAUC ISR $240 \mathrm{~min}^{\mathrm{b}}$ & $683 \pm 212$ & $706 \pm 206$ & 0.6 & 0.4 \\
\hline \multicolumn{5}{|l|}{ AUC proinsulin/AUC insulin ratio } \\
\hline AUC proinsulin/AUC insulin $240 \mathrm{~min}$ & $0.17 \pm 0.06$ & $0.19 \pm 0.09$ & 0.4 & 0.3 \\
\hline IAUC proinsulin/IAUC insulin $240 \mathrm{~min}$ & $0.16 \pm 0.06$ & $0.18 \pm 0.09$ & 0.7 & 0.4 \\
\hline
\end{tabular}

Data are means $\pm \mathrm{SD}$

${ }^{a}$ Calculated using a linear regression model, adjusting for fasting plasma glucose, BMI and age

${ }^{\mathrm{b}}$ Data were log-transformed prior to analysis

proinsulin levels during the meal test. Yet we did not see any significant differences in insulin levels, insulin/proinsulin ratio or proinsulin when we adjusted for HOMA-IR. Therefore, this may suggest that the rs7903146 T allele of TCF7L2 partly acts through decreased transcription of PCSK1 and PCSK2 and thereby via decreased processing of key hormones in glucose metabolism [22]. However, this association may also be a result of increased insulin secretion which, as previously mentioned, may be a consequence of including only glucose-tolerant individuals.

We did not find significantly reduced levels of plasma GLP-1, GLP-2 or GIP during the standardised meal test in carriers of the risk $\mathrm{T}$ allele. These findings are also in line with previous studies [20, 21, 28]. In fact, in the fasting state, we observed an increase in the plasma levels of GLP$2(p=0.02)$. GLP-2 is expressed in equimolar ratios with GLP-1 in entero-endocrine cells, yet GLP-2 is not known to possess major insulinotropic effects [45]. Rather, GLP-2 has glucagonotropic effects [45] and has effects on nutrient absorption and intestinal mucosal functionality [46]. Thus, there is no clear relationship between the observed decrease in fasting glucose and the increased GLP-2 in the fasting state.

Increased levels of plasma GIP during the meal test were seen among TCF7L2 TT carriers. This may be an adaptive response, possibly to overcome a reduction in GIP-R 
expression. Previously, impaired incretin effects among $\mathrm{T}$ allele carriers have been demonstrated [19, 28]. Furthermore, reduced insulinotropic effects of both GLP-1 and GIP among individuals with the rs7903146 risk allele based on a hyperglycaemic clamp with co-infusion of GLP-1 and GIP have been demonstrated [21]. Moreover, a recent study among 18 non-diabetic individuals undergoing an OGTT found a reduction in the incretin effect as well as a $50 \%$ reduction in beta cell responsiveness to glucose [20]. Thus, the increased level of GIP observed may be a response to reduced beta cell responsiveness among TT allele carriers. Interestingly, it has recently been suggested that GIP may have a more important role in type 2 diabetes pathogenesis than previously recognised, supported by observations that patients undergoing bariatric surgery experience resolution of type 2 diabetes as well as blunted postprandial GIP secretion [47]. Thus, plasma GIP concentrations are not decreased in type 2 diabetes, as observed for GLP-1, but rather, GIP might be hypersecreted [48] while high-fat-fed animals with decreased GIP actions are protected against hyperglycaemia and impaired glucose tolerance [49]. Bearing this in mind, there is increasing evidence to suggest that $T C F 7 L 2 \mathrm{~T}$ variants partly mediate their effect through reduced production of GLP-1R and the GIP-R in the pancreatic beta cell [27], possibly by alterations in alternative splicing actions $[10,11]$. Thus, we suggest that one of the physiological consequences of having the rs7903146 TT genotype is elevated levels of GIP, possibly arising as a result of downregulated beta cell GIP-R.

Based on the established effect of the $\mathrm{T}$ allele on the development of type 2 diabetes, it may be surprising that we did not detect a more severe effect of having the TCF7L2 $\mathrm{T}$ allele on measures of glucose homeostasis. This may, however, be a consequence of including only 62 individuals. Furthermore, none of the presented data was corrected for multiple testing. Even though some of the tests are not independent, it should be kept in mind that this multiple testing is prone to generating statistical type 1 errors.

In conclusion, our data indicate that multiple defects in glucose homeostasis are present among glucose-tolerant men carrying the high-risk TCF7L2 rs7903146 TT genotype. These individuals have increased levels of plasma glucose in response to a meal challenge despite having lower fasting plasma glucose levels, decreased processing of proinsulin and elevated GIP secretion.

Acknowledgements The study was supported by Novo Nordisk, the University of Copenhagen and Novartis. We thank A. Forman, T. Lorentzen and M. Stendal for technical assistance, G. Lademann for secretarial assistance and A. Vølund (Charlottenlund, Denmark) for mathematical and statistical advice.

Duality of interest The authors declare that there is no duality of interest associated with this manuscript.

\section{References}

1. Hattersley AT, Pearson ER (2006) Pharmacogenetics and beyond. The interaction of therapeutic response, $\beta$ cell physiology and genetics in diabetes. Endocrinology 147:2657-2663

2. Florez JC (2008) Newly identified loci highlight beta cell dysfunction as a key cause of type 2 diabetes: where are the insulin resistance genes? Diabetologia 51:1100-1110

3. Boesgaard TW, Gjesing AP, Grarup N et al (2009) Variant near ADAMTS9 known to associate with type 2 diabetes is related to insulin resistance in offspring of type 2 diabetes patientsEUGENE2 Study. PLoS ONE 4:e7236

4. Grarup N, Rose CS, Andersson EA et al (2007) Studies of association of variants near the $H H E X, C D K N 2 A / B$, and $I G F 2 B P 2$ genes with type 2 diabetes and impaired insulin release in 10,705 Danish subjects: validation and extension of genome-wide association studies. Diabetes 56:3105-3111

5. Grarup N, Andersen G, Krarup NT et al (2008) Association testing of novel type 2 diabetes risk-alleles in the JAZF1, CDC123/CAMK1D, TSPAN8, THADA, ADAMTS9, and NOTCH2 loci with insulin release, insulin sensitivity and obesity in a population-based sample of 4,516 glucose-tolerant middleaged Danes. Diabetes 57:2534-2540

6. Frayling TM, Timpson NJ, Weedon MN et al (2007) A common variant in the FTO gene is associated with body mass index and predisposes to childhood and adult obesity. Science 316:889-894

7. Rung J, Cauchi S, Albrechtsen A et al (2009) Genetic variant near IRS1 is associated with type 2 diabetes, insulin resistance and hyperinsulinemia. Nat Genet 41:1110-1115

8. Helgason A, Pálsson S, Thorleifsson G et al (2007) Refining the impact of TCF7L2 gene variants on type 2 diabetes and adaptive evolution. Nat Genet 39:218-225

9. Grant SF, Thorleifsson G, Reynisdottir I et al (2009) Variant of transcription factor 7-like 2 (TCF7L2) gene confers risk of type 2 diabetes. Nat Genet 38:320-323

10. Osmark P, Hansson O, Jonsson A, Rönn T, Groop L, Renström E (2009) Unique splicing pattern of the TCF7L2 gene in human pancreatic islets. Diabetologia 52:850-854

11. Prokunina-Olsson L, Welch C, Hansson O et al (2009) Tissuespecific alternative splicing of TCF7L2. Hum Mol Genet 18: 3795-3804

12. Clevers $H(2006) \mathrm{Wnt} / \beta$-Catenin signaling in development and disease. Cell 127:469-480

13. Yi F, Brubaker PL, Jin T (2005) TCF-4 mediates cell type-specific regulation of proglucagon gene expression by beta-catenin and glycogen synthase kinase-3beta. J Biol Chem 280:1457-1464

14. García-Martínez JM, Chocarro-Calvo A, Moya CM, GarcíaJiménez C (2009) WNT/beta-catenin increases the production of incretins by entero-endocrine cells. Diabetologia 52:1913-1924

15. Kirkpatrick CL, Marchetti P, Purrello F et al (2010) Type 2 diabetes susceptibility gene expression in normal or diabetic sorted human alpha and beta cells: correlations with age or BMI of islet donors. PLoS ONE 5:e11053

16. Nauck MA, Homberger E, Siegel EG et al (1986) Incretin effects of increasing glucose loads in man calculated from venous insulin and C-peptide responses. J Clin Endocrinol Metab 63:492-498

17. Dunning BE, Gerich JE (2007) The role of alpha-cell dysregulation in fasting and postprandial hyperglycemia in type 2 diabetes and therapeutic implications. Endocr Rev 28:253-283

18. Pearson ER (2009) Translating TCF7L2: from gene to function. Diabetologia 52:1227-1230

19. Schäfer SA, Tschritter O, Machicao $F$ et al (2007) Impaired glucagon-like peptide-1-induced insulin secretion in carriers of transcription factor 7-like 2 (TCF7L2) gene polymorphisms. Diabetologia 50:2443-2450 
20. Villareal DT, Robertson H, Bell GI et al (2010) TCF7L2 variant rs7903146 affects the risk of type 2 diabetes by modulating incretin action. Diabetes 59:479-485

21. Pilgaard K, Jensen CB, Schou JH et al (2009) The T allele of rs7903146 TCF7L2 is associated with impaired insulinotropic action of incretin hormones, reduced $24 \mathrm{~h}$ profiles of plasma insulin and glucagon, and increased hepatic glucose production in young healthy men. Diabetologia 52:1298-1307

22. Loos RJ, Franks PW, Francis RW et al (2007) TCF7L2 polymorphisms modulate proinsulin levels and beta-cell function in a British Europid population. Diabetes 56:1943-1947

23. González-Sánchez JL, Martínez-Larrad MT, Zabena C, PérezBarba M, Serrano-Ríos M (2008) Association of variants of the TCF7L2 gene with increases in the risk of type 2 diabetes and the proinsulin:insulin ratio in the Spanish population. Diabetologia 51:1993-1997

24. Kirchhoff K, Machicao F, Haupt A et al (2008) Polymorphisms in the TCF7L2, CDKAL1 and SLC30A8 genes are associated with impaired proinsulin conversion. Diabetologia 51:597-601

25. Stancáková A, Kuulasmaa T, Paananen J et al (2009) Association of 18 confirmed susceptibility loci for type 2 diabetes with indices of insulin release, proinsulin conversion, and insulin sensitivity in 5,327 nondiabetic Finnish men. Diabetes 58:2129-2136

26. Stolerman ES, Manning AK, McAteer JB et al (2009) TCF7L2 variants are associated with increased proinsulin/insulin ratios but not obesity traits in the Framingham Heart Study. Diabetologia 52:614-620

27. Shu L, Matveyenko AV, Kerr-Conte J, Cho JH, McIntosh CH, Maedler K (2009) Decreased TCF7L2 protein levels in type 2 diabetes mellitus correlate with downregulation of GIP- and GLP-1 receptors and impaired beta-cell function. Hum Mol Genet 18:2388-2399

28. Lyssenko V, Lupi R, Marchetti P et al (2007) Mechanisms by which common variants in the TCF7L2 gene increase risk of type 2 diabetes. J Clin Invest 117:2155-2163

29. Lee SH, Demeterco C, Geron I, Abrahamsson A, Levine F, ItkinAnsari P (2008) Islet specific Wnt activation in human type II diabetes. Exp Diabetes Res 2008:728763

30. Jørgensen T, Borch-Johnsen K, Thomsen TF, Ibsen H, Glümer C, Pisinger C (2003) A randomized non-pharmacological intervention study for prevention of ischaemic heart disease: baseline results Inter99. Eur J Cardiovasc Prev Rehabil 10:377-386

31. Orskov C, Rabenhøj L, Wettergren A, Kofod H, Holst JJ (1994) Tissue and plasma concentrations of amidated and glycineextended glucagon-like peptide I in humans. Diabetes 43:535-539

32. Deacon CF, Nauck MA, Meier J, Hücking K, Holst JJ (2000) Degradation of endogenous and exogenous gastric inhibitory polypeptide in healthy and in type 2 diabetic subjects as revealed using a new assay for the intact peptide. J Clin Endocrinol Metab $85: 3575-3581$

33. Hartmann B, Johnsen AH, Orskov C, Adelhorst K, Thim L, Holst JJ (2000) Structure, measurement, and secretion of human glucagon-like peptide-2. Peptides 21:73-80

34. Holst JJ (1982) Evidence that enteroglucagon (II) is identical with the C-terminal sequence (residues 33-69) of glicentin. Biochem J 207:381-388
35. Hovorka R, Koukkou E, Southerden D, Powrie JK, Young MA (1998) Measuring pre-hepatic insulin secretion using a population model of C-peptide kinetics: accuracy and required sampling schedule. Diabetologia 41:548-554

36. van Cauter E, Mestrez F, Sturis J, Polonsky KS (1992) Estimation of insulin secretion rates from C-peptide levels. Comparison of individual and standard kinetic parameters for C-peptide clearance. Diabetes 41:368-377

37. Hovorka R, Soons PA, Young MA (1996) ISEC: a program to calculate insulin secretion. Comput Methods Programs Biomed 50:253-264

38. Munoz J, Lok KH, Gower BA et al (2006) Polymorphism in the transcription factor 7-like 2 (TCF7L2) gene is associated with reduced insulin secretion in nondiabetic women. Diabetes 55:3630-3634

39. Palmer ND, Lehtinen AB, Langefeld CD et al (2008) Association of TCF7L2 gene polymorphisms with reduced acute insulin response in Hispanic Americans. J Clin Endocrinol Metab 93:304-309

40. Rasmussen-Torvik LJ, Pankow JS, Jacobs DR Jr, Sinaiko AR (2009) Preliminary report: No association between TCF7L2 rs7903146 and euglycemic-clamp-derived insulin sensitivity in a mixed-age cohort. Metabolism 58:1369-1371

41. Saxena R, Gianniny L, Burtt NP et al (2006) Common single nucleotide polymorphisms in TCF7L2 are reproducibly associated with type 2 diabetes and reduce the insulin response to glucose in nondiabetic individuals. Diabetes 55:2890-2895

42. Wang J, Kuusisto J, Vänttinen $M$ et al (2007) Variants of transcription factor 7-like 2 (TCF7L2) gene predict conversion to type 2 diabetes in the Finnish Diabetes Prevention Study and are associated with impaired glucose regulation and impaired insulin secretion. Diabetologia 50:1192-2000

43. Wegner L, Hussain MS, Pilgaard K et al (2008) Impact of TCF7L2 rs7903146 on insulin secretion and action in young and elderly Danish twins. J Clin Endocrinol Metab 93:4013-4019

44. Florez JC, Jablonski KA, Bayley N et al (2006) Diabetes Prevention Program Research Group. TCF7L2 polymorphisms and progression to diabetes in the Diabetes Prevention Program. N Engl J Med 355:241-250

45. Meier JJ, NAUCk MA, Pott A et al (2006) Glucagon-like peptide 2 stimulates glucagon secretion, enhances lipid absorption, and inhibits gastric acid secretion in humans. Gastroenterology 130:44-54

46. Sinclair EM, Drucker DJ (2005) Proglucagon-derived peptides: mechanisms of action and therapeutic potential. Physiology (Bethesda) 20:357-365

47. Knop FK (2009) Resolution of type 2 diabetes following gastric bypass surgery: involvement of gut-derived glucagon and glucagonotropic signalling? Diabetologia 52:2270-2276

48. NAUCk MA (2009) Unraveling the science of incretin biology. Eur J Intern Med 20(Suppl 2):S303-S308

49. Irwin N, Flatt PR (2009) Evidence for beneficial effects of compromised gastric inhibitory polypeptide action in obesityrelated diabetes and possible therapeutic implications. Diabetologia 52:1724-1731 